\title{
Fronteira, direitos humanos e territórios tradicionais em Rondônia (Amazônia Brasileira) ${ }^{1}$
}

\section{Frontera, derechos humanos y territorios tradicionales en Rondônia (Amazonia Brasileña)}

\section{Frontier, human rights and traditional territories in Rondônia (Brazilian Amazonia)}

\author{
Ricardo Gilson da Costa Silva² (1), Amanda Michalski ${ }^{3}$ (1), \\ Luciano Ítalo Tavares de Souza ${ }^{4}$ (1) y Luís Augusto Pereira Lima ${ }^{5}$ (1)
}

\begin{abstract}
RESUMO
Neste início de século, a contínua marcha do capitalismo na Amazônia brasileira atinge as Áreas Protegidas, espaços destinados à preservação, à conservação da natureza, e proteção aos territórios tradicionais dos povos amazônicos. Essas dinâmicas territoriais ampliam as pressões sociopolíticas e econômicas nos espaços institucionalizados a garantir formas sociais de uso coletivo da terra e da natureza, que diretamente asseguram a proteção dos serviços ambientais para a sociedade. Analisa-se esse fenômeno empírico no estado de Rondônia, localizado na Amazônia meridional brasileira, problematizando esses processos nos territórios dos povos indígenas e seringueiros (comunidade tradicional). Conclui-se que a expansão da fronteira promovida pelos grupos econômicos (pecuária, madeira, grileiros, mineração e soja), com apoio do Estado, atingem a proteção ambiental e cultural dos povos amazônicos com fortes transgressões às leis de ordenamento territorial, cujo resultado institui um processo social vinculado à violência, ao crime ambiental e à negação dos direitos humanos e territoriais dos grupos sociais diretamente afetados.
\end{abstract}

Palavras-chave: Amazônia, Povos Amazônicos, Espaço Agrário, Direitos Humanos.

A pesquisa financiada pelas instituições: FAPERO, DHJUS/EMERON, CAPES

Professor da Universidade Federal de Rondônia - UNIR/Brasil. Doutor em Geografia Humana (USP). Coordenador do Grupo de Pesquisa em Gestão do Território e Geografia Agrária da Amazônia - GTGA (http://www.gtga.unir.br/). E-mail: rgilson@unir.br

Geógrafa, Mestranda no Programa de Pós-Graduação em Geografia - PPGG/UNIR. Bolsista CAPES. Pesquisadora do GTGA/UNIR. E-mail: michalskiO3geo@gmail.com

Graduando em Geografia/UNIR. Bolsista PIBIC/CNPq. Acadêmico do GTGA/UNIR. E-mail: lucianoits22@gmail.com

Doutor em Geografia (UNIR), Pesquisador do GTGA/UNIR. E-mail: aplluisster@gmail.com 


\title{
RESUMEN
}

En el inicio de este siglo, la marcha continua del capitalismo en la Amazonia brasileña alcanza áreas protegidas, espacios destinados a la preservación y conservación de la naturaleza, y la protección de los territorios tradicionales de los pueblos amazónicos. Estas dinámicas territoriales aumentan las presiones sociopolíticas y económicas en los espacios institucionalizados para garantizar formas sociales de uso colectivo de la tierra y la naturaleza, que garantizan directamente la protección de los servicios ambientales para la sociedad. Analizamos este fenómeno empírico en el estado de Rondônia, localizado en el sur de la Amazonia brasileña, problematizando estos procesos en los territorios de los pueblos indígenas y recolectores de caucho (comunidad tradicional). Se concluye que la expansión de la frontera promovida por los grupos económicos (pecuaria, madera, acaparamiento de tierras, minería y soja), con el apoyo del Estado, alcanza la protección ambiental y cultural de los pueblos amazónicos con fuertes transgresiones a las leyes de organización territorial, cuyo resultado establece un proceso social vinculado a la violencia, al crimen ambiental y la negación de los derechos humanos y territoriales de los grupos sociales directamente afectados.

Palabras clave: Amazonia, Pueblos Amazónicos, Espacio Agrario, Derechos Humanos.

\begin{abstract}
In the beginning of this century, the continuous march of capitalism in the brazilian Amazonia reaches protected areas, spaces destined to the preservation and conservation of nature, and protection to the traditional territories of the Amazonian peoples. These territorial dynamics increase socio-political and economic pressures in the institutionalized spaces to guarantee social forms of collective use of land and nature, which directly guarantee the protection of environmental services for the society. We analyze this empirical phenomenon in the state of Rondônia, located in the southern brazilian Amazonia, problematizing these processes in the territories of indigenous peoples and rubber tappers (traditional community). We conclude that the expansion of the frontier promoted by economic groups (livestock, madeira, land-grabbers, mining and soya), with the support of the State, reaches the environmental and cultural protection of the Amazonian peoples with strong transgressions to the laws of territorial ordering, the result of which a social process linked to violence, environmental crime and the denial of human and territorial rights of social groups directly affected.
\end{abstract}

Keywords: Amazonia, Amazonian Peoples, Agrarian Space, Human Rights.

\section{Introdução}

A partir da década de 1960, a Amazônia brasileira vem experimentando ordenamentos territoriais que produzem formas de apropriação e dominação do mundo rural, no qual a mercantilização da natureza e da terra compõem a lógica territorial do Estado (agências públicas) e das grandes empresas (mineradoras, hidrelétricas, agropecuárias, construtoras, madeireiras). Trata-se de projetar e formar territórios da socialidade do capital, que se expande para todas as sub-regiões amazônicas.

Nesse processo, a contínua marcha do capitalismo na Amazônia brasileira atinge as Áreas Protegidas, espaços destinados à preservação, à conservação da natureza, e à proteção dos territórios tradicionais dos povos amazônicos (indígenas, seringueiros, ribeirinhos, quilombolas, extrativistas, dentre outros grupos). Essas dinâmicas territoriais agrárias ampliam as pressões sociopolíticas e econômicas nos espaços institucionalizados para garantir formas sociais de uso 
coletivo da terra e da natureza, que diretamente assegura a proteção dos serviços ambientais à sociedade.

Pode-se verificar tais dinâmicas, de modo geral, em toda a Amazônia, desde as sub-regiões mais próximas dos centros econômicos radiadores, quanto nas áreas em que as estradas ainda não chegaram, cujo acesso se faz por barcos (Costa Silva et al., 2018). Desse modo, analisa-se esse fenômeno no estado de Rondônia, localizado na Amazônia meridional brasileira, problematizando os processos de invasões nos territórios dos povos indígenas e seringueiros (comunidade tradicional). Neste caso, aborda-se os processos modeladores da fronteira que se realizam no norte do estado de Rondônia, especificamente no município de Porto Velho, onde a Terra Indígena Karipuna, a Reserva Extrativista Jacy-Paraná e a Floresta Nacional do Bom Futuro sofrem as pressões de agentes econômicos traduzidas nas invasões de Áreas Protegidas, grilagens, desmatamento, extração madeireira e agropecuária.

Baseado nos fenômenos empíricos estudados, o objetivo deste texto é analisar a relação da expansão da fronteira, ordenamentos territoriais e direitos humanos em Rondônia, priorizando os sujeitos sociais aviltados em seus direitos mais básicos, ou seja, os grupos sociais que formam os povos e as comunidades da Amazônia, com especial atenção aos povos indígenas e aos seringueiros da área de estudo. Como procedimentos metodológicos, adotou-se o i) trabalho de campo e observação direta da área de estudo, ii) coleta de dados quantitativos (pecuária, desmatamento, extração madeireira) junto aos bancos de dados de instituições públicas (Instituto Brasileiro de Geografia e Estatística-IBGE e Instituto Nacional de Pesquisas Espaciais-INPE), os quais foram trabalhados com os iii) softwares Excel (estatística), Philcarto (cartomática) e ArcGIS (geoprocessamento). iv) A revisão bibliográfica priorizou os estudos regionais referentes aos grandes projetos de infraestrutura, expansão de fronteira e impactos sociogeográficos.

Assim, além desta introdução, o texto está dividido em três seções, seguido das considerações finais. Na primeira seção, analisa-se a expansão da fronteira e ordenamentos do território na Amazônia, problematizando a transformação da região em espaço nacional da economia extrativa, cujas dinâmicas econômicas atingem os territórios dos povos amazônicos. Na segunda seção, aprofunda-se o entendimento desse processo para o estado de Rondônia, evidenciando o crescimento da pecuária, extração madeireira, desmatamento, mercado de terra e agronegócio. Em seguida, na terceira seção, problematiza-se como a expansão da fronteira atinge os territórios tradicionais e Unidades de Conservação em Rondônia, priorizando a Terra Indígena Karipuna e Reserva Extrativista Jacy-Paraná, na região do município de Porto Velho, capital do estado de Rondônia. Na quarta seção, de modo resumido, elenca-se alguns apontamentos para a pesquisa em geografia, direitos humanos e território, com vistas ao entendimento das lutas dos povos amazônicos na defesa de seus territórios frente às pressões e violências produzidas pelas forças do capital.

Conclui-se que a expansão da fronteira promovida pelos grupos econômicos (pecuaristas, madeireiros, grileiros, mineradoras e agronegócios), com apoio do Estado, atinge a proteção ambiental e cultural dos povos amazônicos com fortes transgressões às leis de ordenamento territorial, cujo resultado institui um processo social vinculado à violência, ao crime ambiental e ao indeferimento dos direitos humanos e territoriais dos grupos sociais diretamente afetados. 


\section{Amazônia, fronteira e ordenamentos do território}

Desde a década de 1960, a formação socioespacial da Amazônia vem passando por aceleradas transformações coordenadas pelo Estado brasileiro, que numa perspectiva geopolítica de ocupação humana e econômica instituiu processos de socialidade do capital no interior da floresta Amazônica, produzindo uma geografia do desmatamento e das agressões aos territórios tradicionais dos povos amazônicos. A abertura de estradas, migração e colonização agrícola, articulada aos grandes projetos de infraestruturas (mineração, energia, agropecuária) e expansão urbana, configuraram o que Raffestin (1993) qualificou de sistema territorial de poder do Estado. Esses grandes projetos conformaram os tentáculos do Estado na apropriação e dominação do território (Becker, 2004).

Nesse sentido, fronteira e ordenamento territorial foram conceitos mobilizados para compreender a ordem política, econômica e social que se impunha à Amazônia. Por fronteira, entende-se a expansão espacial do capital em regiões periféricas, no qual a natureza e a terra são metamorfoseadas em mercadorias, a exemplo da Região Amazônica (Becker, 2004; Costa Silva, 2017; Kohlhepp, 2002; Mello \& Théry, 2001). Assim, pode-se afirmar que há uma ordem territorial que reconfigura as funções econômicas e sociais da Amazônia no sentido de aprofundar a extração dos recursos naturais. Nesses termos, as dinâmicas territoriais que atingem o espaço agrário amazônico estão indissociavelmente articuladas às contínuas apropriações dos recursos naturais, evidenciando estratégias de territorialização dos grupos sociais (migrantes, colonos, camponeses), agentes hegemônicos (latifundiários, grandes empresas) e Estado (diversas agências estatais) que reproduzem a expansão da fronteira (Coy et al., 2017). Desse modo, contemporaneamente, ao tempo em que se expande a fronteira, pari passu, tem-se as pressões socioeconômicas em Áreas Protegidas (Unidades de Conservação, Terras Indígenas e Quilombolas), que tendem a gerar conflitos territoriais e expropriações dos grupos sociais mais vulneráveis, como os povos indígenas, seringueiros, ribeirinhos e quilombolas, além de outras comunidades tradicionais amazônicas (Figura Nº1).

Para Kohlhepp (2002), o processo de organização territorial na Amazônia apresenta duas categorias: a estatal e a privada. A primeira objetivou atrair investidores para a região Norte do Brasil, buscando promover projetos que pudessem colaborar com a melhoria da infraestrutura centralizada no transporte rodoviário. Tal medida tinha o intuito de legitimar a integração da região amazônica ao restante do país. A segunda, por meio de incentivos fiscais, efetivou-se nos megaprojetos de exploração agrominerais e agroflorestais. Esses processos, de modo geral, instituíram um ordenamento do território que expressou, e ainda expressa, a condição da Amazônia como fronteira de recursos, na medida em que sua função na divisão territorial do trabalho é a economia de produtos primários, ou com pouco valor agregado (Costa Silva \& Conceição, 2017). Qualificando o ordenamento territorial, Trindade Júnior e Madeira (2016: 37-38) propõem uma periodização das dinâmicas territoriais centrais que transformaram a Amazônia: "os polos de crescimento (até a década de 1980), os eixos de integração e desenvolvimento (a partir da segunda metade do década de 1990), [...] e os zoneamentos ecológicos-econômicos (a partir, principalmente, dos anos 2000)". Kholhepp (2002) subdivide esses processos em seis fases (Quadro No1). 
Figura N01.

Mapa das Áreas Protegidas na Amazônia Brasileiro (2020)

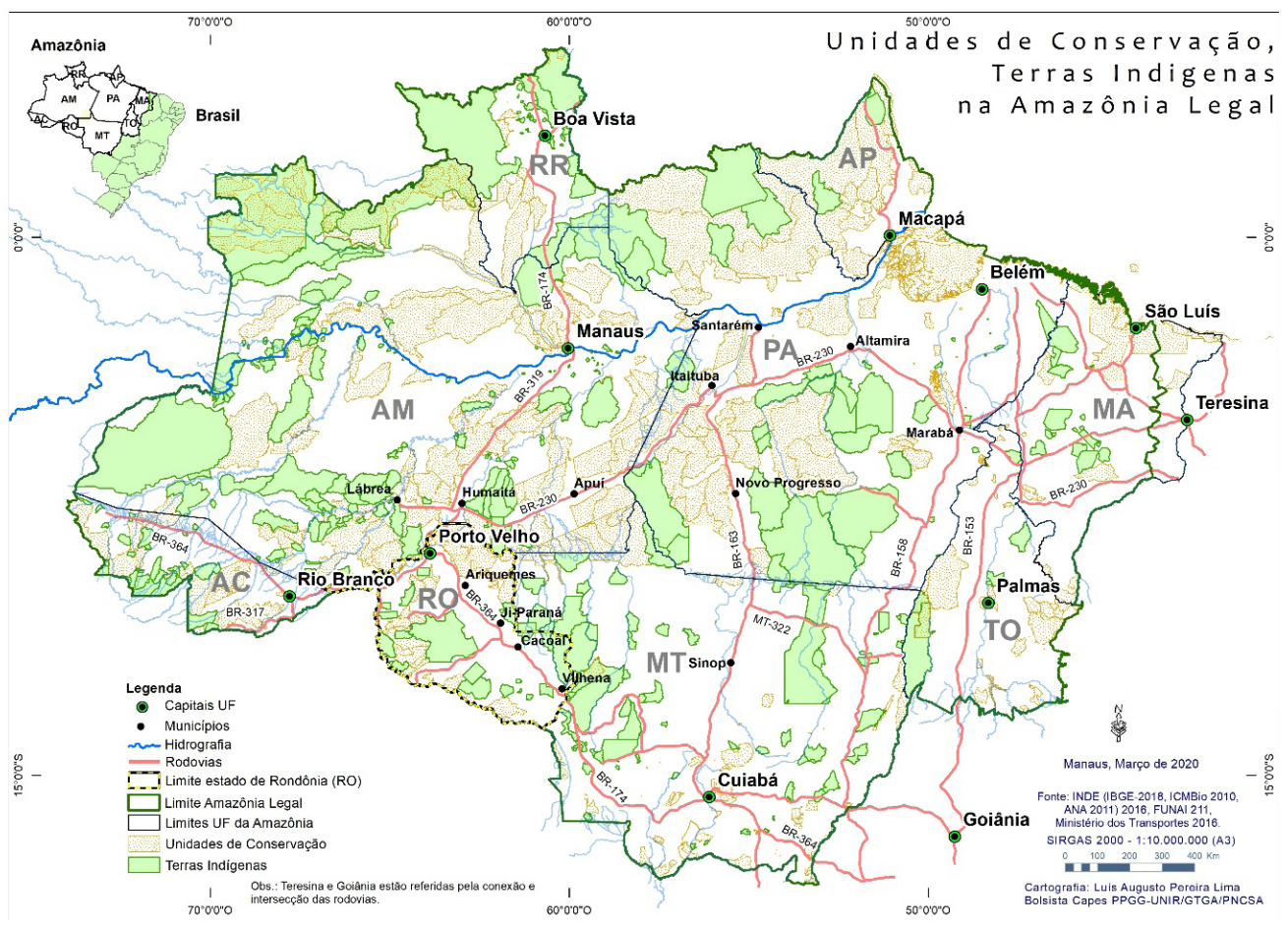

Elaboração: Autores.

Quadro $N^{\circ} 1$ :

Fases de ordenamento territorial na Amazônia

\begin{tabular}{|c|c|l|}
\hline Fase & Período & \multicolumn{1}{c|}{ Objetivo } \\
\hline $1^{a}$ & $\begin{array}{c}\text { Primeira metade da } \\
\text { década de } 1970\end{array}$ & $\begin{array}{l}\text { Construção de grandes rodovias / Transamazônica, a Perime- } \\
\text { tral Norte, Cuiabá-Santarém e Cuiabá-Porto Velho-Manaus. }\end{array}$ \\
\hline $2^{a}$ & Entre 1974 e 1980 & $\begin{array}{l}\text { Implementação dos Programas de Polo Agropecuário e Agro- } \\
\text { minerais da Amazônia (POLAMAZÔNIA) }\end{array}$ \\
\hline $3^{a}$ & $\begin{array}{c}\text { Nos primeiros anos da } \\
\text { década de } 1980\end{array}$ & $\begin{array}{l}\text { Implementação do Programa Integrado de Desenvolvimento do } \\
\text { Noroeste do Brasil (POLONOROESTE) }\end{array}$ \\
\hline $4^{a}$ & $\begin{array}{c}\text { Década de } 1980 \\
\text { Início da década de } \\
1990\end{array}$ & $\begin{array}{l}\text { Megaprojetos minerais e agropecuários com destaque para o } \\
\text { Projeto Grande Carajás. }\end{array}$ \\
\hline $6^{a}$ & $\begin{array}{l}\text { Organização e implementação do Programa Piloto Internacio- } \\
\text { nal para Conservação das Florestas Tropicais brasileiras (PPG-7) }\end{array}$ \\
\hline década de 1990 & $\begin{array}{l}\text { Com base nos Eixos Nacionais de Integração e Des- } \\
\text { envolvimento (ENIDs) incorporados pelos Programas } \\
\text { Brasil em Ação e Avança Brasil. }\end{array}$ \\
\hline
\end{tabular}

Fonte: Kholhepp (2002). Organizado pelos autores. 
Por sua vez, Mello \& Théry (2001) contribuem com a periodização das transformações amazônicas propondo três fases, quais sejam: 1) na década de 1970 a ênfase esteve na infraestrutura do principal modal de transporte brasileiro, o rodoviário, bem como em projetos de colonização; 2) na década de 1980, por sua vez, o ordenamento territorial foi estruturado com base nos Polos de Crescimento, a exemplo do Polamazônia e Polonoroeste; 3 ) e finalmente, na segunda metade da década de 1990, as políticas territoriais promoveram os corredores de exportação, que foram responsáveis por reconfigurações espaciais/territoriais. Os autores descrevem as políticas territoriais ligadas aos corredores de exportação como "políticas contraditórias", haja vista apresentarem visões diferentes de desenvolvimento econômico e social para a Amazônia. No final da década de 1990 e início dos anos 2000 buscou-se promover um desenvolvimento pautado em políticas ambientais que, em parte, se configuraram pelo viés ricardiano ${ }^{6}$ de valoração dos recursos naturais e, ao mesmo tempo, perpetuando formas arcaicas de acumulação do capital. Acúmulo esse que foi marcado pela expansão da fronteira agrícola e desterritorialização dos povos indígenas e comunidades tradicionais dos territórios culturais.

As fases descritas do ordenamento territorial da Amazônia traduzem-se em impactos ambientais que amplificam os dados de desmatamento, queimadas, rápida degradação do solo e danos irreparáveis aos territórios tradicionais dos povos indígenas, comunidades quilombolas, ribeirinhos e seringueiros. Na medida em que o processo de expansão da fronteira se reveste de um sentido de "desbravamento" e "pioneirismo", onde os sujeitos se sentem heróis por abrirem estradas e criarem vilas e cidades, há toda uma engrenagem que molda a configuração socioterritorial da Amazônia.

Evidencia-se que todos os grandes projetos de infraestrutura na Amazônia trouxeram como lógica de ordenamento do território a socialidade do capital, sempre com apoio do Estado, no sentido de desconstituir os elementos amalgamadores dos povos amazônicos, ou seja, a expropriação dos territórios e da natureza. Na escala local, no mundo vivido das populações urbanas e rurais, partindo sempre as decisões de cima para baixo, os grandes projetos cristalizam nos lugares a solidariedade organizacional das empresas (Santos \& Silveira, 2001), promovendo um processo de descaracterização da região, uma (des)amazonização da Amazônia.

Em resumo, esses são alguns dos processos que destacamos para compreender a forma como o ordenamento territorial da região amazônica se configurou e continua a se configurar, ao passo que promovem descaracterização social, cultural e ambiental, com forte intuito de pressionar os povos originários e comunidades tradicionais da Amazônia (Figura №1).

Atualmente, os instrumentos jurídicos de ordenamento territorial dos territórios protegidos (Unidades de Conservação, Terras Indígenas e Áreas Quilombolas) estão sendo erodidos pelo Estado neoliberal, de modo a prevalecer a forma corporativa-econômica que promove a agenda de enfraquecimento desses territórios, o que termina por fragilizá-los para atender os mecanismos

Teoria de renda da terra e renda de escassez conceituadas por David Ricardo em seu livro "Princípios da economia política e tributação" escrito em 1817. Em suma, onde a demanda for maior que a oferta do recurso haverá cobrança de um preço público; é uma renda de escassez apropriada pelo dono, neste caso o Estado (Reis; Santin, 2007). 
de expansão da economia de fronteira e do mercado global de commodities. No caso de Rondônia, objeto de análise deste texto, compõem esse processo a pecuária, soja, madeira, mineração e o mercado de terras, sendo, pois, laboratório de políticas públicas aplicadas pelo Estado, com profundas mudanças, o que podemos designar como mundo agrário.

\section{Rondônia: a marcha da pecuária, madeira, terra e soja}

Historicamente no Brasil, a pecuária é representada como uma das principais atividades responsáveis pela ocupação do território brasileiro, vista como um modelo de produção das áreas de expansão da fronteira agrícola, ancorada na intensa apropriação de terras e demais recursos naturais (Furtado, 2005; Barcellos et al., 2008; Becker, 2004). Segundo Barcellos et al. (2008:52), a pecuária extensiva, na década de 1970, era compreendida como uma atividade que garantia segurança "em função de sua liquidez e baixo risco". Dessa maneira, a pecuária representava uma reserva de capital, uma vez que a dupla (boi e terra) correspondia à função de preservar ativos fixos, ou imobilizados, de reserva de valor, garantindo, dessa maneira, uma maior estabilidade econômica ao produtor.

Esse perfil da pecuária ainda repercute no aumento da área de pastagem, o que significa a incorporação de áreas de florestas pelas patas do boi. Com isso, promove-se tanto o deslocamento da fronteira quanto o aumento das pressões político-territoriais nas Áreas Protegidas. Sabe-se que a pecuária extensiva na Amazônia está relacionada à baixa aplicabilidade de insumos tecnológicos, limitando a produtividade das pastagens e do rebanho. Isto significa que o manejo inadequado (solo, planta e animal) gera maior desgaste ambiental, indicando ser um dos fatores do deslocamento dessa atividade na fronteira. Por certo, a forma difundida pela exploração espacial da pecuária se correlaciona à baixa eficiência e menor produtividade (Ferreira et al., 2010).

No estado de Rondônia, a conversão de floresta em pastagens associa-se às dinâmicas espaciais dos grãos (soja e milho), que promovem a valorização da terra tanto para agricultura quanto para a pecuária (Costa Silva \& Conceição, 2017). Em outras palavras, a expansão da fronteira agrícola se associa com o deslocamento da pecuária extensiva e, consequentemente, com o aumento nos conflitos socioterritoriais nos limites das Áreas Protegidas, ampliando a pressão econômica nos territórios tradicionais dos povos amazônicos. A fronteira realiza-se conjuntamente com o processo de especulação de terras, em que grandes grupos compram terras que servirão como reserva de valor (lanni, 1979). 
Figura № 2: Evolução do rebanho bovino em Rondônia (1990 a 2018)

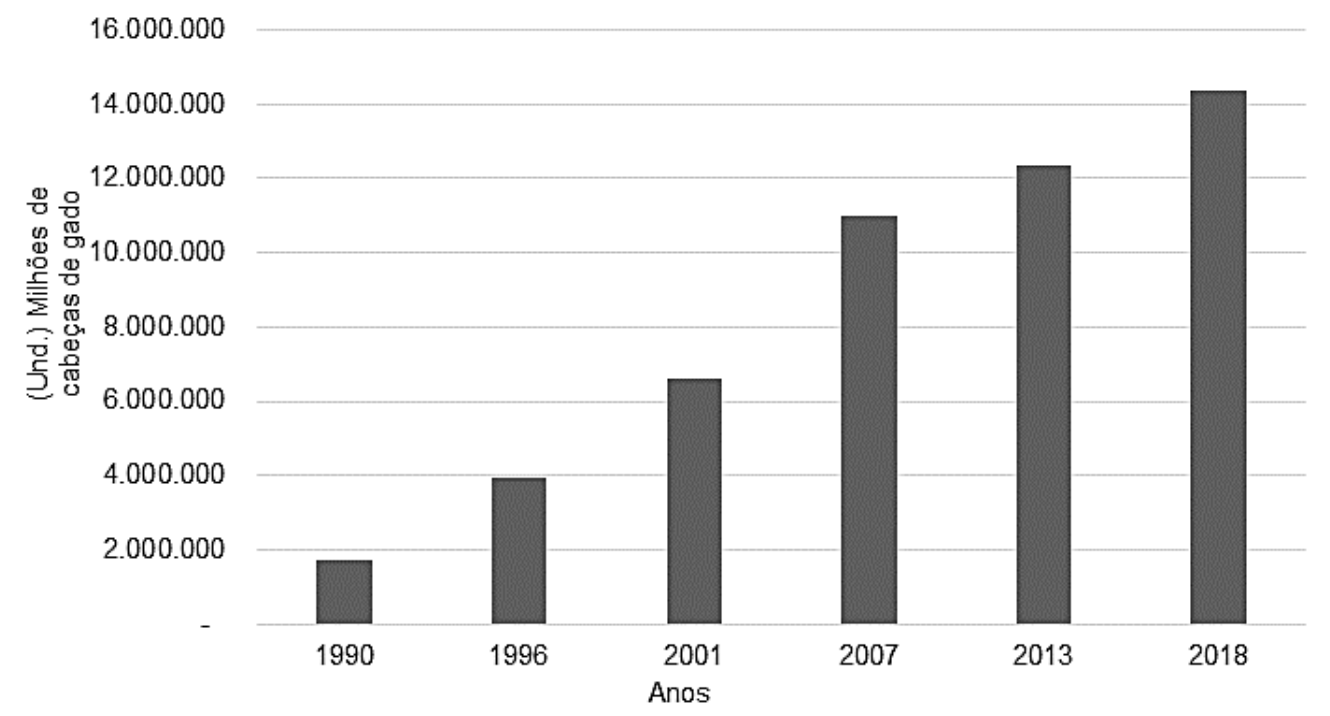

Fonte: PPM/SIDRA /IBGE, 2019. Elaborado pelos autores.

Como objeto de análise, o estado de Rondônia é marcado por uma forte presença do capital agropecuário. De acordo com o Instituto Brasileiro de Geografia e Estatística -IBGE o setor agropecuário representa $13,89 \%{ }^{7}$ do Produto Interno Bruto (PIB), ocupando a terceira posição na composição do PIB estadual (IBGE, 2016). Apesar da sua colocação no ranking da economia estadual, este setor aparece como o principal indutor das transformações no espaço regional, desde a expansão da fronteira à migração campo-campo e campo-cidade (Costa Silva et al., 2017). A pecuária se destaca como umas das principais atividades que envolve todos os estratos fundiários, sendo pecuária (carne) e soja (farelo e grãos) os principais produtos de exportação. A pecuária extensiva em Rondônia alcança 62,17\% (IBGE, 2017) do número de estabelecimentos agropecuários. No Gráfico 01 podemos observar, nos últimos 28 anos, o crescimento do efetivo bovino de Rondônia.

O efetivo bovino rondoniense, entre os anos de 1990 e 2018, apresentou 736\% de crescimento. Ao longo desses anos, Rondônia passou de 1.718.697 cabeças para mais de 14 milhões de bovinos, conforme podemos observar no cartograma que indica a distribuição espacial da pecuária em todos os municípios (Figura $\mathrm{N}^{\circ} 3$ ). Este aumento significativo possibilitou que o Estado atingisse a sexta (6) posição no ranking nacional e segunda ( $\left.2^{a}\right)$ posição na Região Norte (IBGE, 2017). Em relação à área de pastagem, com base nos Censos Agropecuários (2006 e 2017), houve um acréscimo de $25 \%$ da área, passando de 4.565 .835 hectares (2006) para 5.740 .063 hectares de pastagens plantadas (2017), o que Ihe permitiu a nona (9a) colocação nacional e a terceira (3a) posição na Região Norte (IBGE, 2017). 
figura $\mathrm{N}^{\circ} 3$

Distribuição espacial da pecuária em Rondônia (1990 e 2018)

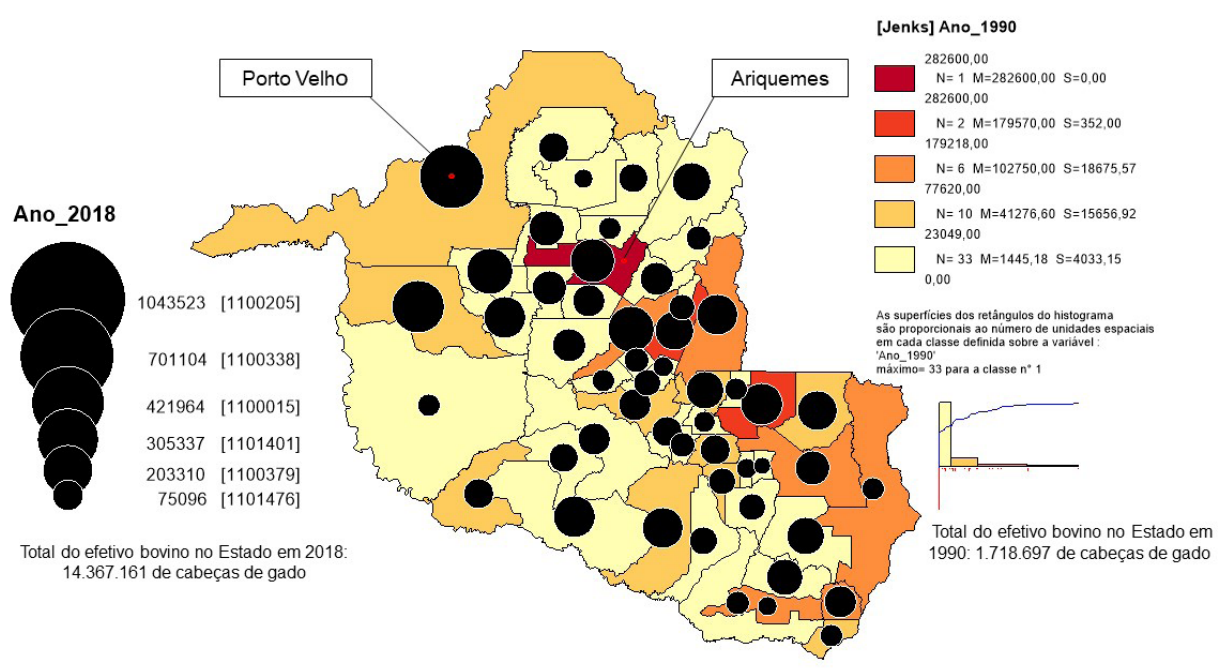

Fonte: IBGE (2020). Organização: Autores. Elaborado com Philcarto: http://philcarto.free.fr/.

Em Rondônia, dos 10 municípios que incorporaram áreas de pastagens, oito estão localizados no norte do estado, com destaque para Cujubim, que apresentou crescimento, no período entre 2006 e 2017, de 155,91\% em área da pecuária. Este município findou o ano de $2018 \mathrm{com} \mathrm{49,80 \%} \mathrm{de}$ aumento de desmatamento, assumindo a primeira posição dos municípios que mais desmataram nos últimos 18 anos. O número de propriedades com pecuária apresentou acréscimo de 19,05\% entre os anos de 2006 e 2017. Salienta-se que a pecuária expressa uma dinâmica territorial pautada na pressão de Áreas Protegidas, sobretudo, quando há um deslocamento espacial do sul para o norte rondoniense, contribuindo, até o ano de 2018, com 38,83\% de desmatamento em Rondônia. Entretanto, cabe acrescentar que essa dinâmica territorial, contraditoriamente, possibilita aos camponeses encontrarem na fronteira uma maneira de reprodução social, territorial e econômica (Costa Silva, 2016; Wanderley, 2014). A pecuária que contribui com a reprodução social camponesa serve também como "manto" para encobrir latifundiários, haja vista que o quantitativo da área destinada à pastagem não expressa melhora na produtividade do rebanho de Rondônia.

Dentre os grupos sociais e econômicos (camponeses, madeireiros, pecuaristas e grileiros) que movimentam a fronteira em Rondônia, iniciaremos com a análise da exploração madeireira. Como anteriormente exposto, a pecuária extensiva, por meio do manejo solo, planta e animal, não apresenta uma produtividade adequada. Além disso, continua exercendo a produção com rápida liquidez, necessitando de reserva de capital, neste caso, representada pela terra, sendo esta, ainda, o principal fator de produção da atividade, o que tende a refletir na permanente busca por novas áreas.

Como dinâmica territorial, essa conversão se dirige às Áreas Protegidas, principalmente nas Reservas Extrativistas e Terras Indígenas, como atualmente se verifica no norte de Rondônia, pro- 
cesso que decorre, sobretudo, do aumento do desmatamento ilegal praticado nessas áreas para fins tanto da exploração madeireira quanto às atividades agropecuárias e mercado de terras.

Esse processo contribui para o aumento dos conflitos socioterritoriais, visto que os recursos naturais em Áreas Protegidas passam a ser uma mercadoria essencial na expansão da fronteira. Diante disso, os territórios tradicionais dos seringueiros e indígenas, como veremos mais adiante, são "negligenciados" pelo Estado (Executivo, Legislativo e Judiciário), na medida em que essas áreas, sendo usurpadas pelos agentes da grilagem e do crime ambiental, atingem os direitos humanos e territoriais dos povos amazônicos.

A exploração madeireira (legal e ilegal) assegura significativamente o deslocamento da fronteira em Rondônia. Assim como a pecuária, a madeira faz parte da tríade (pecuária, madeira e terra) que movimenta a fronteira, o que garantiu, em 2018, a terceira posição no comércio nacional, com $11 \%$ do volume total explorado no país. Os dois primeiros colocados são os estados de Mato Grosso, com 34\% e Pará, com 28\% dos 11.616. $286 \mathrm{~m}^{3}$ de madeira em toras extraídas no Brasil.

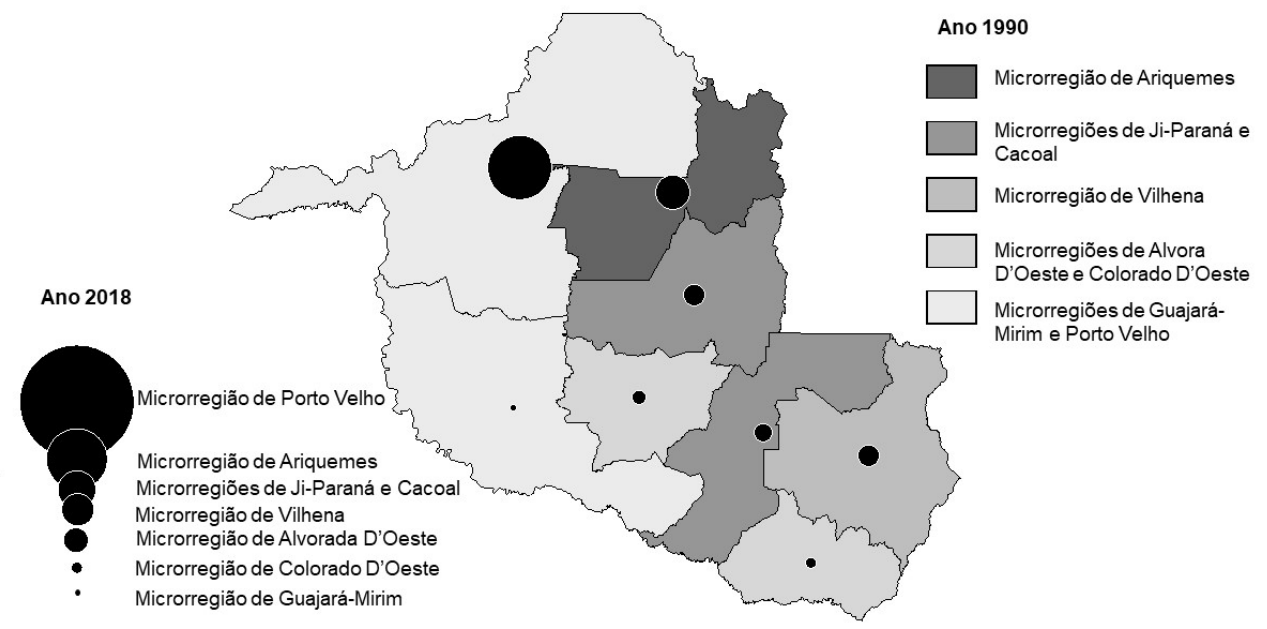

Fonte: IBGE (2020). Organização: Autores. Elaborado com Philcarto: http://philcarto.free.fr/.

Na Figura N4 estão indicadas as oito microrregiões de Rondônia, com dados referentes aos anos de 1990 e 2018, que respaldam o período com maior exploração madeireira no estado. No ano de 1990 as duas microrregiões com maior produção de exploração madeireira foram Ariquemes (35\%) e Cacoal (20\%), essas microrregiões são compostas por 16 municípios, 7 e 9 respectivamente. No ano de 2018, a microrregião de Porto Velho foi responsável por $60 \%$ da extração estadual. Nesta microrregião, os municípios com maiores volumes de exploração são: Porto Velho (45\%), Candeias do Jamary (29\%) e Cujubim (11\%). A microrregião de Ariquemes, no mesmo ano, foi responsável por $17 \%$ do volume explorado. Nesta microrregião, os municípios com maior repre- 
sentatividade na extração de madeira são: Machadinho D'Oeste (45\%), Rio Crespo (18\%) e Ariquemes (15\%). Ao correlacionarmos essas informações com os dados referentes ao desmatamento, identificamos que grande parte desses municípios que compõem essas duas microrregiões, com maior volume de extração de madeireira, estão entre os 10 municípios com maior percentual de desmatamento e maior variação de incremento do desmatamento, em relação aos últimos 18 anos.

Com base nas informações coletadas na plataforma do Instituto Nacional de Pesquisas Espaciais (INPE), dos 52 municípios de Rondônia, 14 já possuem mais de $80 \%$ de sua extensão territorial desmatada ao longo dos últimos 50 anos (1970-2019). Também se destaca que três desses municípios encontram-se ao longo do eixo da BR 364, cuja formação territorial se deve aos núcleos dos projetos de colonização, sendo eles os municípios de Jaru, Presidente Médici e Ouro Preto do Oeste. Entretanto, os outros 11 municípios não estão ao longo da BR-364, mas em função do deslocamento da pecuária, no ano de 2018 incorporaram maiores áreas desflorestadas.

Segundo Michalski (2018), grande parte da madeira extraída no município de Porto Velho pode estar relacionada à extração ilegal. A autora apresenta essa hipótese com base em um estudo realizado pela Esalq/USP8, publicado no ano de 2018, que aponta a fraude para legalizar a extração de árvores protegidas na Amazônia. Os dados analisados na referida pesquisa indicam a falsificação do selo $\mathrm{FSC}^{9}$, que libera licenças para madeiras extraídas, sendo essas, "legalizadas" no mercado. Portanto, nos $45 \%$ do volume de madeira em tora extraído no município de Porto Velho, podem estar incluídos os $29,45 \%$ do desmatamento da região. Além disso, o município registra a contínua ação criminosa de madeireiras que praticam crime ambiental (roubo de madeira) na Terra Indígena Karipuna, Resex Jacy-Paraná e Flona do Bom Futuro.

Esses grupos (madeireiros, fazendeiros, grileiros) buscam se apropriar dos recursos da natureza com a expansão da fronteira agrícola, o que implica no acréscimo de terras ao capital (Costa Silva, 2017). Dessa forma, por meio da expansão da fronteira, viabiliza-se a expropriação do campesinato nas demais sub-regiões rondonienses, favorecendo a incorporação de áreas ao agronegócio da soja. A expansão da fronteira promove o deslocamento da pecuária, acarretando tanto a marcha do desflorestamento quanto o surgimento dos conflitos socioterritoriais.

Adiciona-se ao processo o aquecimento do mercado de terras, sobretudo quando os produtores de soja almejam ampliar a área de produção, como atualmente ocorre nas microrregiões de Ariquemes e Porto Velho. Desta maneira, promove-se a elevação do preço da terra, acarretando pressões econômicas e expropriações dos pequenos produtores/campesinato. Portanto, a valorização das commodities agrícolas gera na Amazônia uma acentuada elevação no preço da terra, percebida como reserva de valor compatível aos agentes hegemônicos que, por sua vez, promovem um caráter especulativo e rentista do mercado (Costa Silva \& Conceição, 2017).

No plano global, essa dinâmica é um reflexo da crise econômica ocorrida entre os anos de 2007 e 2010, o que obrigou o capital financeiro a investir em commodities agrícolas, minerais e compras de terras, uma verdadeira corrida em busca de recursos naturais. Dessa forma, amplia-se a especulação no mercado de terras, proporcionando assim, maior busca por reservas de valor

Escola Superior de Agricultura Luiz de Queiroz da Universidade de São Paulo (USP).

FSC Sistema de Certificação Florestal. 
que, consequentemente, indicam o aumento do latifúndio no Brasil, com impactos territoriais diretos na Amazônia.

Na escala regional, a expansão da fronteira agrícola, em Rondônia, busca formas de ramificação por meio da incorporação de áreas, ou seja, florestas transformadas em pastagens, com degradação ambiental (desmatamento e queimadas), assim como, amplia os conflitos socioterritoriais que objetivam erodir os direitos territoriais dos povos indígenas e comunidades tradicionais (seringueiros, ribeirinhos e quilombolas).

\section{A fronteira atinge os territórios tradicionais em Rondônia}

Nas últimas décadas, o norte/noroeste de Rondônia vem sendo transformado pelas frentes de expansão da pecuária e exploração ilegal de madeira, as quais estamos qualificando de expansão da fronteira. Diante disso, a fronteira se desloca para as Áreas Protegidas, a exemplo da Terra Indígena Karipuna, Reserva Extrativista Jacy-Paraná e Floresta Nacional Bom Futuro, processo que ocorre à medida que o desmatamento avança junto aos limites dessas áreas, levando à perda de serviços ambientais e até mesmo à redução ou redefinição de limites da área protegida (Imazon, 2018; Costa Silva, 2016).

Esse processo também atinge os direitos territoriais e, por conseguinte, os direitos humanos dos povos amazônicos, especificamente dos povos indígenas e dos seringueiros em análise neste estudo. A fronteira chegou nessas áreas protegidas, primeiro com o roubo de madeira, depois com tentativas de grilagens de terras, seguido da pecuária, o que tem contribuído com o aumento do desmatamento nestas Áreas Protegidas e comprometendo as condições culturais, econômicas, sociais e ambientais dos povos amazônicos afetados.

A exploração ilegal da madeira funciona como uma maneira de obtenção imediata do valor na metamorfose da natureza em mercadoria, pois, a ilegalidade desta atividade que se desvia dos caminhos formais - pagamento de impostos, manejo florestal e outros serviços ambientais - alimenta toda uma cadeia de transgressões que prejudica e impacta os territórios tradicionais (CIMI, 2019). Segundo os dados do Programa de Monitoramento do Desmatamento da Floresta Amazônica Brasileira por Satélite (PRODES), entre 1988 e 2017, uma área de 2.823 hectares (ha) dos 152 mil hectares da TI Karipuna já foram desmatados, sendo que, $40 \%$ deste total, o que corresponde a 1.139ha, ocorreu entre 2015 e 2017, o que indica que, nos últimos anos, houve uma aceleração da pressão territorial para desorganizar e invadir a Terra Indígena (Figura $N^{\circ} 5$ ).

Como hipótese, indica-se que a expansão da pecuária nesta região, e consequente "corrida" pela terra púbica, foi motivada pelo deslocamento do agronegócio da soja do sul para o norte de Rondônia, fazendo com que a pecuária e o deslocamento populacional fossem empurrados para novas áreas rurais (Costa Silva et al., 2017). Nesse sentido, amplia-se os conflitos socioterritoriais e se verifica a dominação do território pelo capital agropecuário, assim como suas influências nas ações políticas que tendem à redução, fragilização e ou extinção de áreas protegidas, sejam Unidades de Conservação, Terras Indígenas ou Territórios Quilombolas (Costa Silva, 2017). 
Conforme o Figura 04, as Áreas Protegidas em questão são alvos de atos criminosos da agrobandidagem que atua em toda a Amazônia. As Áreas Protegidas estão localizadas entres dois distritos do município de Porto Velho - União Bandeirantes e Rio Pardo - cuja economia se desenvolve, principalmente, a partir da pecuária e extração ilegal de madeira. De acordo com o Zoneamento Socioeconômico e Ecológico de Rondônia - ZSEE-RO (Rondônia, 2010), União Bandeirantes está na subzona 2.1 (área de conservação dos recursos naturais passível de uso sob manejo sustentável) e Rio Pardo está na subzona 3.2 (áreas destinadas às Unidades de Conservação de Proteção Integral).

Figura No5.

Norte de Rondônia: Distritos de União Bandeirantes e Rio Pardo.

Áreas Protegidas TI Karipuna, RESEX Jacy-Paraná e FLONA do Bom Futuro (2020)

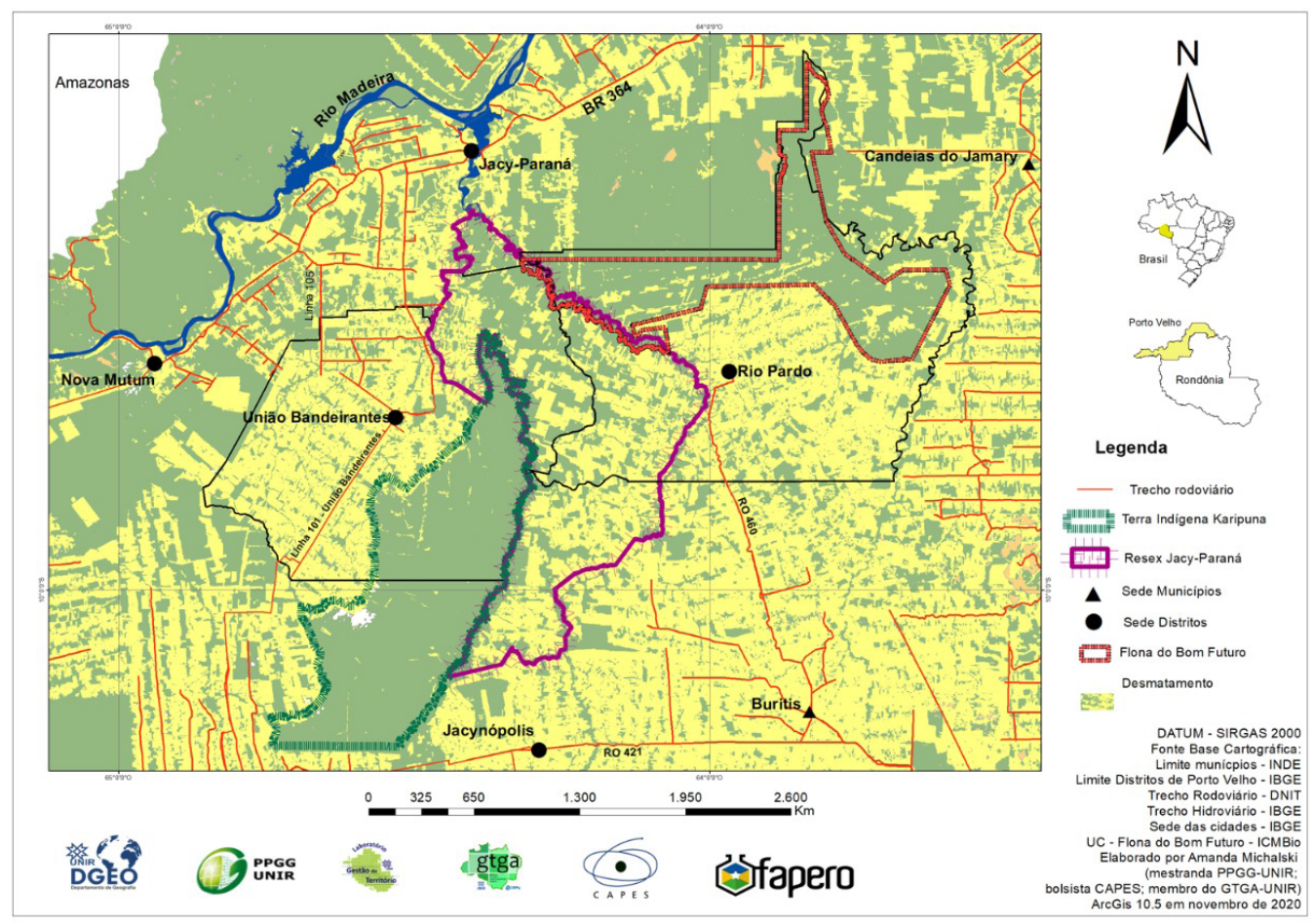

Fonte: Elaboração do Autores.

A Reserva Extrativista Jacy-Paraná - território dos seringueiros - vem sendo gradativamente destruída pela invasão de madeireiros, fazendeiros e pecuaristas, potencializando o desmatamento (Funai, 2018; Santana; Silva, 2019), situação de difícil controle ambiental que se encaminha à irreversibilidade. Essa destruição não causa somente impactos ambientais, mas impacta a vida de quem nela habita (os seringueiros), que com frequência são ameaçados de expulsão e de expropriação do território. Neste caso, trata-se de um processo contínuo de desterritorialização da comunidade tradicional. A RESEX Jacy-Paraná tem uma área de 196.897,00ha, que até o ano de 2000 estava com pouca pressão antrópica, cujo desmatamento indicava apenas 778 hectares. $O$ deslocamento da fronteira agrícola (pecuária, madeira e grilagem de terra) fez o desmatamento 
disparar, de modo que em 2016, a área desflorestada já correspondia a 77.536,31 hectares, e em 2017 apresentou 98.665 hectares desmatados, o que equivale a quase 50\% da RESEX (Santana \& Silva, 2019; ISA, 2019).

Os seringueiros da RESEX praticam, prioritariamente, a coleta de frutos nativos (cupuaçu, tucumã, açaí, bacuri), coleta de castanha e a extração da borracha, assim como caça e pesca, e mesmo a reduzida atividade agrícola. Todas essas atividades podem servir tanto à obtenção de renda quanto à subsistência, instaurando as territorialidades desses grupos no interior do que ainda existe de floresta e do território tradicional que resiste à expansão da fronteira, sendo a RESEX uma das mais invadidas e impactadas pela grilagem de terras em Rondônia.

A Terra Indígena Karipuna, assim como a RESEX, vêm sendo alvo de exploração ilegal de madeira em partes de sua área, cujo limite abre caminho para o alcance dos infratores que enxergam a floresta como fonte de acumulação (Funai 2018). Tais processos se relacionam a grupos organizados, verdadeiras agromilícias que agem por meio de invasões coordenadas para grilar a terra indígena, tentando fazer da TI Karipuna um laboratório da agrobandidagem na Amazônia, de modo a produzir um domínio político somado a uma situação social com vista a tornar irreversível a grilagem de terras, como ocorreu e ocorre na Resex Jacy-Paraná e na Flona do Bom Futuro. Essa é a aposta e o projeto territorial da agrobandidagem que age em Rondônia e na Amazônia brasileira. Umas da estratégia da agrobandidagem é incentivar a expansão da fronteira por meio do deslocamento do campesinato (posseiros), induzindo esses grupos a desbravarem áreas ambientais regulamentadas, com a intenção de pressionar o governo a alterar os limites de Unidades de Conservação e os tipos de usos descritos nos instrumentos de gestão territorial.

As ameaças à área indígena são diversas e envolvem desde a pressão menor de caçadores e pescadores, quanto a ação estratégica de madeireiros, grileiros e, em escala nacional, das solicitações de empresas mineradoras para pesquisa com vistas a extração de ouro e estanho (todos em estágio de requerimento de pesquisa no Departamento Nacional de Produção Mineral - DNPM (Costa Silva \& Lima, 2020). Contudo, o roubo de madeira organizado pela indústria madeireira tem sido o ato mais criminoso e de maior ataque ao território dos Karipuna. Esse processo aumentou nos últimos anos, sobretudo em função conjuntura política do Brasil, em que os ataques aos territórios tradicionais e às Áreas Protegidas, de modo geral, produziram uma onda articulada de pressões políticas para fragilizar esses territórios protegidos. A TI Karipuna tem 153.000ha, com uma população aproximada de 55 indígenas, cuja evolução demográfica tem sido positiva desde 2004. Até o ano de 2000 havia somente 305 ha desmatados, aumentando tal pressão desde 2014 e chegando a 1.426 hectares desmatados em 2017 (ISA, 2019). Recentemente, no ano de 2018 e 2019, a agrobandidagem leiloou lotes na área indígena Karipuna com organização social e serviço de topografia e geoprocessamento, o que acendeu o alerta nas instituições públicas no sentido de produzir uma resposta rápida e eficaz.

Toda essa pressão econômica e territorial levou os órgãos públicos de fiscalização, controle e judicial, somada às denúncias feitas pelas organizações indígenas e organizações sociais de apoio aos povos indígenas, a manifestarem preocupações quanto aos atos de violências, de invasões e de possível genocídio na TI Karipuna. Desde 2016, as organizações sociais de apoio aos povos indígenas, inúmeras vezes, denunciaram junto ao Ministério Público Federal, Polícia Federal e Funai os incessantes mecanismos de invasões na TI Karipuna. Em 2018 e 2019, as instituições 
públicas formaram uma força tarefa para investigar e combater o crime organizado, a agrobandidagem e a agromilícia que atuavam na área indígena:

A Força-tarefa Amazônia, do Ministério Público Federal (MPF), articulou, nos últimos seis meses, quatro grandes operações para proteção de terras indígenas e unidades de conservação em Rondônia. Duas das operações são referentes à terra indígena Karipuna, uma foi na Floresta Nacional do Bom Futuro e a outra refere-se à terra indígena Uru-Eu-Wau-Wau. Ao todo foram 30 pessoas e oito empresas denunciadas por crimes como invasão de terras indígenas, lavagem de dinheiro, organização criminosa, dano ambiental, entre outros. $\mathrm{Na}$ Operação Floresta Virtual o foco foi a exploração predatória de madeiras na terra indígena Karipuna e os métodos de lavagem empregados pelas serrarias de União Bandeirantes, localidade que é um distrito de Porto Velho. Descobriu-se durante as investigações que os responsáveis pelas madeireiras desenvolveram um grande esquema de falsificação de documentos de origem florestal (DOFs), com inserção de informações falsas no Sistema DOF, sistema informatizado administrado pelo Ibama (MPF, 16/10/2019).

A agrobandidagem tem atuado em várias sub-regiões rondonienses com o propósito de invadir Áreas Protegidas e criar situações de apelo social para que o Estado aceite a conversão de áreas florestais em espaço da agropecuária, da extração madeireira, da mineração e do mercado de terras.

A narrativa de que os pequenos produtores/campesinato precisam de terras para trabalho se tornou comum nesse processo. Todavia, a estratégia frequentemente é de usá-los para garantir no médio prazo um mercado de terras à agropecuária e ao agronegócio, assim como, justificar a abertura das áreas indígenas à exploração mineral e florestal. Dessa forma, a agrobandidagem, em conjunto com organizações de garimpeiros, inventam o problema mineral em Rondônia.

Outra unidade de conservação que sofreu com esse processo foi a Floresta Nacional do Bom Futuro, que começou a ser ocupada desordenadamente a partir de 1995 e 1997, com a instalação de dois assentamentos do Incra. Seguiram-se várias ocupações irregulares na região, inclusive simuladas por agentes políticos locais que ali montaram currais eleitorais. Dessa forma, esses processos, em 2010, reduziram em mais de $65 \%$ a área da Flona do Bom Futuro. A área original desta Unidade de Conservação era de 280.000ha, e por meio da lei 12.249 de 14 de junho de 2010, teve seus limites reduzidos para 97.357ha. Com a nova delimitação, a degradação ambiental não cessou e, atualmente, expressa um resultado devastador: cerca de $15,13 \%$ da área da Flona, que correspondem a 14.783ha já foram desmatados, registrando a ocupação de 3,5 mil habitantes e 35 mil bovinos ilegais (MMA, 2009; ISA, 2019).

\section{Direitos Humanos e Território: apontamentos para pesquisa}

A questão da fronteira na Amazônia (agrícola, mineral, madeireira, hidroenergético, mercado de terras global) que se direciona às áreas mais distantes e inacessíveis, assusta os povos amazônicos que vivem em seus territórios tradicionais ou culturais. 
Esse deslocamento, as vezes pontual, outras vezes em ritmos acelerados, de certa forma, esgotou o que se debatia anteriormente como "terras devolutas", como terras de ninguém, onde a posse ou a invasão de terras públicas bastaria para impor uma territorialidade, um projeto de território. Em muitas áreas da Amazônia o capital, ou a sociedade do capital chegou primeiro que o Estado e suas normas.

Não devemos esquecer que o primeiro estudo amplo dos recursos naturais da Amazônia, assim como a sua potencialidade, foi realizado no período de 1970/1985, pelo Ministério das Minas e Energia, no âmbito do Projeto RadamBrasil. Nesse período, havia uma recente ocupação na Amazônia, desde a década de 1960, quando a abertura da rodovia Belém-Brasília e a colonização da transamazônica constituíram os elementos iniciais, do que foi qualificado pelas ciências sociais como fronteira e frentes pioneiras.

Nesse processo, os territórios e os povos amazônicos foram ignorados, silenciados, sendo as primeiras vítimas da chamada modernização da Amazônia. Nas décadas de 1980/1990/2000 os ventos do reconhecimento do Estado brasileiro para com esses povos amazônicos se converteram em inúmeras políticas públicas, dentre as quais, certamente, o reconhecimento legal de seus territórios foram as mais importantes, porque entendia e normatizava uma ordem jurídica que garantia aos grupos sociais um território coletivo em suas múltiplas territorialidades.

Passadas décadas, muitas lutas e resistências dos povos indígenas, ribeirinhos, quilombolas, seringueiros, quebradeiras de coco, pescadores, extrativistas, camponeses ribeirinhos, camponeses agroextrativistas e tantos outros grupos sociais que podemos designar como povos amazônicos, seus territórios se encontram ameaçados pelas forças econômicas que querem transformar a natureza, a exuberante floresta, os caudalosos rios, em paisagem do fogo, do pasto, dos grãos e das represas, em paisagem da anti-natureza, em paisagem do anti-povo-amazônico.

O debate central, sob nosso entendimento, indica que a questão agrária se reveste de questão territorial, na medida em que a luta é para assegurar os direitos territoriais consolidados pelo Estado brasileiro em Áreas Protegidas, espaço e territórios dos povos amazônicos. A agenda política do agronegócio é rever e destruir esses direitos duramente conquistados pelos povos e comunidades tradicionais amazônicas. (Costa Silva \& Lima, 2020).

As ondas de violências aos povos amazônicos, as pressões econômicas e crimes ambientais contra seus territórios ensejam pesquisas referentes ao reconhecimento das diferenças culturais, dos direitos humanos e da defesa da natureza como processo indissociável à vida coletiva e à reprodução social desses grupos.

Tais processos convergem à indissociabilidade temática dos direitos humanos e direitos territoriais, ao território como condição de vida coletiva. Nesse sentido, o campo de luta, sofrimento e resistências dos seringueiros, como analisado em Rondônia, impõem-se como agenda de pesquisa com vistas a contribuir para o entendimento geral das questões postas, assim como, para a construção de instrumentos de lutas para com os povos amazônicos em suas pautas e desafios sociais e territoriais. 


\section{Considerações finais}

Todos esses processos de grilagem colocam em risco os direitos territoriais de povos indígenas, quilombolas, ribeirinhos, seringueiros, pescadores e outras comunidades tradicionais que dependem da natureza para viver. À medida em que o desmatamento se alastra, a possibilidade de vida nessas áreas tende a diminuir, sobretudo, quando associada à grilagem, há todo tipo de crime e ameaças aos povos amazônicos em seus territórios.

As três Áreas Protegida mencionadas neste estudo (TI Karipuna, RESEX Jacy-Paraná e FLONA do Bom Futuro) estão localizadas no norte de Rondônia, região de expansão da fronteira impulsionada pela extração ilegal de madeira, grilagem de terras e pecuária. Elas cristalizam as ameaças aos territórios protegidos na Amazônia, às disputas por territórios no sentido de se projetar um espaço do agronegócio da soja, considerando que a "demanda" por terra empurra a pecuária e a exploração madeireira para novas frentes, cujo limite parece indicar justamente as Áreas Protegidas. Neste caso, os povos indígenas, as comunidades tradicionais e os setores do campesinato sofrem esse processo de expropriação, violência e crime ambiental em seus territórios.

Os processos moleculares de acumulação do capital que fazem expandir a fronteira atingem os territórios dos povos e comunidades tradicionais amazônicas, constituindo em campo de conflitos sociais que assume escala global. Na medida em que o capital global e seus aliados nas elites locais promovem a pilhagem de áreas públicas destinadas pelo o Estado aos povos amazônicos, o capital tende a não respeitar e a ignorar as bases jurídicas e os ordenamentos territoriais que visam proteger tanto a natureza e seus serviços ambientais, quanto a reprodução social das coletividades que têm nos territórios a condição política de sua existência.

De modo global, as dinâmicas territoriais que aceleram as transformações no mundo agrário amazônico, cujos impactos mais severos atingem os territórios dos povos indígenas e comunidades tradicionais, impõem pensar a relação teórica da geografia com os direitos básicos desses grupos sociais, a articulação do território com direitos humanos e territoriais, condição necessária para se constituir a pesquisa com compromisso social e significados humanos.

\section{Referências bibliográficas}

BARCELOS, A. O.; RAMOS, A.K.B.; VILELA, L. \& MARTHA JUNIOR, G.B. Sustentabilidade da produção animal baseada em pastagens consorciadas e no emprego de leguminosas exclusivas, na forma de banco de proteínas, nos trópicos brasileiros. Revista Brasileira de Zootecnia, 2008, Vol. 37, p. 51-67

BECKER, B. Amazônia: geopolítica na virada do III milênio. Rio de Janeiro: Garamond, 2004.

CIMI. Conselho Indigenista Missionário. Grileiros intensificam invasão na Terra Indígena Karipuna, em Rondônia. Reportagem do Greenpeace Brasil publicada em 24/01/2019. Disponível em https://cimi.org.br/2019/01/grileiros-intensificam-invasao-na-terra-indigena-karipuna-em-rondonia/ Acessado em 20 de março 2020. 
COSTA SILVA, R. G. Agentes, procesos y conflictos en la gestión territorial en el estado de Rondônia (Brasil). Polis, 2016, Vol. 15, N45, p. 319-344

COSTA SILVA, R. G. Da apropriação da Terra ao domínio do território: as estratégias do agronegócio na Amazônia brasileira. International Journal of Development Research, 2017, Vol. 7, №12, p. 17699-17707, 2017.

COSTA SILVA, R. G.; MICHALSKI, A; LIMA, L. A. P.; CONCEICAO, F. S. Geografia das dinâmicas territoriais agrárias de Rondônia. In: Ferreira, G.H.C. (Org.). Geografia Agrária em debate: das lutas históricas às práticas agroecológicas. Jundiaí: Paco Editorial, 2017, p. 143-162.

COSTA SILVA, R.G \& CONCEICAO, F.S. Agronegócio e campesinato na Amazônia brasileira: transformações geográficas em duas regiões nos estados de Rondônia e Pará. GEOGRAPHIA (UFF), 2017, Vol. 19, p. 54-72.

COSTA SILVA, R.G; LIMA, L.A. P; CONCEIÇÃO, F. S. (Orgs). Amazônia: dinâmicas agrárias e territoriais contemporâneas. São Carlos: Editora Pedro \& João, 2018.

COY, M; KLINGLER, M; KOHLHEPP, G. De frontier até pós-frontier: regiões pioneiras no Brasil dentro do processo de transformação espaço-temporal e sócio-ecológico. Confins, 2017, Vol. 30, №30. Disponível em https://journals.openedition.org/confins/11683. Acessado em 23 de outubro de 2019.

FERREIRA, R.R.M; TAVARES FILHO, J.; FERREIRA, V.M. Efeitos de sistemas de manejo de pastagens nas propriedades físicas do solo. Semina: Ciências Agrárias, 2010, Vol. 31, №4, p. 913-932.

FUNAI. Fundação Nacional do Índio. Disponível em: http://www.funai.gov.br/index.php/comunicacao/noticias/5502-operacao-sos-karipuna-investiga-organizacoes-criminosas-que-atuavam-em-terra-indigena-em-rondonia. Acessado em 23 de outubro de 2019.

FURTADO, C. Formação Econômica do Brasil. São Paulo: Companhia Editora Nacional, 2005.

IANNI, O. Colonização e contra-reforma agrária na Amazônia. Petrópolis: Vozes, 1979.

IBGE - Instituto Brasileiro de Geografia e Estatística. Pesquisa do Censo Agropecuário 2006 e 2017 - Pecuária Municipal. Brasil, 2017

IBGE - Instituto Brasileiro de Geografia e Estatística. Produto Interno Bruto - 2016. Brasil, 2016.

IMAZON. Instituto do Homem e Meio Ambiente da Amazônia. Disponivel em https://imazon.org. $\mathrm{br} /$ ?s=\%C3\%A1reas+protegidas\&submit-search=. Acessado em 24 de outubro de 2020.

ISA. Instituto Socioambiental. Plataforma Terras Indígenas do Brasil. Terra Indígena Karipuna. 2019. Disponível em https://terrasindigenas.org.br/pt-br/terras-indigenas/3723\#demografia. Acessado em 24 de outubro de 2020. 
ISA. Instituto Socioambiental. Unidades de Conservação do Brasil. Floresta Nacional do Bom Futuro. ISA, 2019. Disponível em https://uc.socioambiental.org/arp/639. Acessado em 31 de outubro de 2020.

KOHLHEPP, G. Conflitos de interesse no ordenamento territorial da Amazônia brasileira. Estudos Avançados, 2002, Vol. 16, N45, p. 37- 61.

MELLO, N.A. \& THÉRY, H.A armadura do espaço amazônico: eixos e zoneamento. ALCEU, 2001, Vol. 1, N², p. 181- 214.

MICHALSKI, A. Geografia da Pecuária e do desmatamento em Porto Velho: União Bandeirantes e Rio Pardo. Monografia (Graduação em Geografia) - Fundação Universidade Federal de Rondônia. Porto Velho, Rondônia, 2018.

MPF. Força-tarefa Amazônia fez quatro operações e denunciou 30 pessoas e oito madeireiras por crimes em Rondônia. Publicado em 16 de outubro de 2019. Disponível em http://www.mpf.mp.br/ro/ sala-de-imprensa/noticias-ro/forca-tarefa-amazonia-fez-quatro-operacoes-e-denunciou-30-pessoas-e-oito-madeireiras-por-crimes-em-rondonia. Acessado em 31 de outubro de 2020.

PRODES/INPE. Desflorestamento nas Unidades de Conservação. 2018. Disponivel em http://www. dpi.inpe.br/prodesdigital/prodesuc.php Acessado em 31 de outubro de 2020.

PRODES/INPE. Desflorestamento nos municípios. 2018. Disponível em: http://www.dpi.inpe.br/ prodesdigital/prodesmunicipal.php Acessado em 19 de agosto 2019.

RAFFESTIN, C. Por uma Geografia do Poder. São Paulo: Ática, 1993.

REIS, A. \& SANTIN, M.F.C.L. A teoria da renda da terra ricardiana: um marco unificador entre as economias da poluição e dos recursos naturais. Perspectiva Econômica, 2007, Vol. 3, №2, p. 6581.

RONDÔNIA. Governo do Estado de Rondônia. Secretaria de Estado do Desenvolvimento Ambiental. 21 anos de Zoneamento Socioeconômico e ecológico do Estado de Rondônia: planejamento para o desenvolvimento sustentável e proteção ambiental. SEDAM, Porto Velho, 2010.

SANTANA, R.S. \& SILVA, S.C.P.G. Avaliação do avanço do desmatamento na Reserva Estadual Extrativista Jaci-Paraná - RO, no período de 1996 a 2016. Terr@Plural, 2019, Vol. 13, №1, p. 93-105.

TRINDADE JÚNIOR, S.C. \& MADEIRA, W.V. Polos, eixos e zonas: cidades e ordenamento territorial na Amazônia. PRACS Revista Eletrônica de Humanidades do Curso de Ciências Sociais da UNIFAP, 2016, Vol. 9, Nº1, p. 37- 54.

WANDERLEY, M.N.B. O campesinato Brasileiro: uma história de resistência. RESR, 2014, Vol. 52, Nº 1, p. 25-44. 
